\title{
Films of Poly (L - Lactic Acid) / \\ Poly(Hydroxybutyrate-co-Hydroxyvalerate) Blends:
}

\section{In vitro Degradation}

\author{
B.M.P. Ferreira ${ }^{\mathrm{a}}$, C.A.C. Zavaglia ${ }^{\mathrm{b}}$, E.A.R.Duek ${ }^{\mathrm{b}}{ }$ \\ ${ }^{a}$ Departamento de Engenharia de Materiais, Faculdade de Engenharia Mecânica, \\ Universidade Estadual de Campinas, C.P. 6122 13083-970 Campinas - SP, Brazil \\ ${ }^{\mathrm{b}}$ Centro de Ciências Médicas e Biológicas, \\ Pontifícia Universidade Católica de São Paulo, 18030-230 Sorocaba - SP, Brazil
}

Received: November 16, 2000; Revised: January 18, 2001

\begin{abstract}
Biocompatible and biodegradable polymers have been studied in the last few years with good clinical success in the fixation and stabilization of bone fractures. The understanding and the control of the polymeric prosthetic degradation process and the effect of its degradation products in the organism are crucial for the success of the implant. In this present work, blends of PLLA/PHBV, obtained in several compositions by casting of solvent, obtaining samples in the form of films. The samples were characterized by the analysis of TGA, DSC, DMA and SEM. The results obtained showed that the PLLA/PHBV blends are immiscible, and present a discrete separation by microscopy. The blends obtained showed porous fracture surfaces. It is noticed that PLLA begins its degradation in a few weeks (around 2 weeks), unlike PHBV, where it was possible to observe eventual degradation up to 53 weeks. It was also observed that the blend increased its crystallinity with degradation.
\end{abstract}

Keywords: Poly(L-lactic acid), Poly(hydroxybutyrate-co-hydroxyvalerate), blends, in vitro degradation

\section{Introduction}

$\operatorname{Poly}(\alpha$-hydroxy esters) such as poly(L-lactic acid) (PLLA), poly(glycolic acid) (PGA) and poly(DL- lactic -co- glycolic acid) (PLGA) are currently being investigated as materials for the regeneration of several tissues including cartilage, bone, liver and intestine ${ }^{1}$.

Poly( $\alpha$-hydroxy esters) decompose by bulk degradation. The first measurable event that occurs during bulk degradation is the loss of strength because molecular weight decreases. The polymer chains are soluble in the extracellular fluid when the molecular weight is below 7000. At this time the material has little strength and the polymer begins to fragment due to local mechanical stresses ${ }^{1}$.

When the degradation process produces particles of approximately $20 \mu \mathrm{m}$, multinucleated cells or macrophages can phagocytose them. Those particles that are not phagocytosed continue to degrade and decrease in size. As lactic

e-mail: eliduek@fem.unicamp.br

Trabalho apresentado no $14^{\circ}$ CBECIMAT , Águas de São Pedro, Dezembro 2000 and glycolic acid are released, there is a danger of a local decrease in the $\mathrm{pH}$ if the area is not well vascularized ${ }^{1}$.

The reabsorbable fixation device eliminates the need to remove the osteosynthetic materials by surgery, after the fracture has healed. The polymeric prosthesis must have the following properties: appropriate chemical and physical structures to satisfy the desirable useful lifetime in the body; absence of contaminant substance and possibility of being sterilized. Moreover, the polymer must not induce tumor formation, thrombus formation or inflammation in the surrounding tissues. All these requirements greatly reduce the number of polymers, which are potential candidates for biomedical applications ${ }^{2}$.

There are many situations in which ostensibly inert polymers are used for the construction of prostheses and implanted in body tissues where it is intended that they remain for a considerable period of time. However, it frequently happens that these polymers are, in practice, slightly degraded by the physiological environment. An understanding of this phenomenon is of great importance 
because the fact that the biocompatibility and functionality of the implant may be compromised ${ }^{3}$.

In biomedical applications, environmental stability tends to be particularly important in three areas: processing, sterilization and long term implantation. Degradation during processing is primarily thermal, radiative, or hydrolytic, depending upon the sterilization technique used. In the physiological environment, the only feasible degradation mechanisms are hydrolysis and oxidation. For hydrolysis to occur the polymer must contain hydrolytically unstable bonds and show some degree of hydrophilicity. For hydrolysis to occur "in vivo" a further constraint is applied, that the reaction should proceed at a $\mathrm{pH}$ value around 7.4 and at a temperature of $37{ }^{\circ} \mathrm{C}$. In vivo degradation of polymers is also complicated by the possible involvement of agents as enzymes ${ }^{3}$.

Current degradable polymers such as polylactic acid and polyglycolic acid may not be universally suitable for use in orthopedics, due to the nature of their degradation pattern. A newly developed naturally occurring polymer of hydroxybutyric acid or polyhydroxybutyrate (PHB) is showing great promise, due to its long term degradation profile at high molecular weights ${ }^{4,5}$.

The degradation of PHB is strongly influenced by $\mathrm{pH}$ and the $\mathrm{pH}$ effects must be determined if the material is to be used in the body, because relatively large localized $\mathrm{pH}$ changes occur which could alter the degradation profile of the material. Another critical factor of this material is that the analysis of the molecular weight shows a bimodal distribution, which gives rise to a complex degradation pattern ${ }^{4}$.

Implantation of a material will cause many responses, which will result in very rapid surface changes, due to the absorption of various cellular and/or proteinaceous materials on the implant surface. This absorption process on the polymer surface is mediated by the physic-chemical status of the implant surface ${ }^{4,6}$.

Blends exhibit advantageous physical and mechanical properties that each individual polymer does not have. Depending on the thermodynamic compatibility of the two chosen polymers, phase-separated polymers can be obtained, imposing different morphologies and matrix characteristics $^{7,8}$.

Polymer blends with both semi-crystalline components are more complex. They forge a new way for the study of the relationships between the behavior of the phases and the development of the structure in polymer mixtures. The formation and morphology of the semicrystalline/semicrystalline state that involves the crystallization of different polymers, each one in a specific temperature ${ }^{9}$, is of great interest.

The properties of the blends depend mainly on thermodynamic miscibility. If the polymers are immiscible, the properties will depend not only on the properties of each component, but also on the morphology and adhesion between the phases ${ }^{10}$.

The aim of this work is to study the "in vitro" degradation of the PLLA/PHBV blend in different compositions and to analyze their behavior relative to the hydrolytic degradation.

\section{Experimental}

Poly(L-lactic acid), molecular weight $\mathrm{Mw}=100.000$ (Medisorb - Dupont), and poly(3-hydroxybutyrate-co-3hydroxyvalerate), with $12 \%$ of hydroxyvalerate (Aldrich), were used in this research. Methylene chloride (Synth) was employed as solvent.

\subsection{Blend preparation}

The blends PLLA/PHBV were prepared by dissolving the polymer separately in methylene chloride $(5 \% \mathrm{~W} / \mathrm{V})$ under stirring for approximately one hour. The final composition of PLLA/PHBV blends were 100/0, 60/40, 40/60 and $0 / 100(\mathrm{~W} / \mathrm{W})$, which were stirred for one hour for complete homogenization. The PLLA/PHBV mixture was poured onto a glass plate. The glass plate containing the blend in solution was placed in a glass box to dry and saturated with vapor from the solvent (approximately $20 \mathrm{~mL}$ ). After evaporation of the solvent, membranes, approximately $0.14 \mathrm{~mm}$ thick, were obtained. The membranes were maintained under vacuum, following the drying phase.

\subsection{In vitro degradation}

Films were immersed in glass tubes containing phosphate buffer solution ( $\mathrm{pH}=7.4)$, for specific periods $(1,4$, $8,12,16,24,36$ and 53 weeks). After each period of degradation, the samples were removed, washed with distilled water for four hours and vacuum dried for 48 hours. Samples were characterized by Thermogravimetric Analysis (TGA), Differential Scanning Calorimetry (DSC), Dynamic Mechanical Analysis (DMA) and Scanning Electron Microscopy (SEM).

\subsection{Thermogravimetic analysis (TGA)}

The TGA analysis was carried out in a STA 409C of NETZSCH - Gerätebau GmbH Thermal Analysis. The samples were heated from the room temperature up to $400{ }^{\circ} \mathrm{C}$ at a heating rate of $10^{\circ} \mathrm{C} / \mathrm{min}$ under helium atmosphere.

\subsection{Differential scanning calorimetry (DSC)}

Thermal transitions of the blends were measured by means of differential scanning calorimetry (DSC) using a STA 409C of NETZSCH - Gerätebau GmbH Thermal Analysis, at a heating rate of $10{ }^{\circ} \mathrm{C} / \mathrm{min}$ in a helium atmosphere. Samples were first heated from 25 to $200{ }^{\circ} \mathrm{C}$. The samples were maintained at this temperature for $5 \mathrm{~min}$, until 
complete melting, eliminating the thermal history of the samples. They were then cooled to $-20{ }^{\circ} \mathrm{C}$ for $5 \mathrm{~min}$ and heated again to $200{ }^{\circ} \mathrm{C}$. The melting temperatures of the two phases and the enthalpy associated with the melting and/or crystallization process were determined.

\subsection{Dynamic mechanical analysis (DMA)}

Dynamic mechanical analysis were performed using a NETZSCH - Dynamic Mechanical Analysis - 242. The samples were cooled to $-25{ }^{\circ} \mathrm{C}$ and soon after heated up to $200{ }^{\circ} \mathrm{C}$, with a heating rate of $5^{\circ} \mathrm{C} / \mathrm{min}$, under air, with a maximal force of $1 \mathrm{~N}$, frequency of $1 \mathrm{~Hz}$ and width of 15 $\mu \mathrm{m}$ using a tension system.

\subsection{Scanning electron microscopy (SEM)}

A JEOL'S electronic microscope JXA 840A (tension of 10 to $20 \mathrm{kV}$ ) was used to observe the upper surfaces, which were coated with a thin layer of gold, using a Sputer Coater BAL-TEC SCD 050.

\section{Results and Discussion}

\subsection{Thermogravimetric analysis (TGA)}

Degradation temperatures for the blends, obtained by TGA curves are shown in Table 1 . Thermal degradation of the samples can be observed in relation to the degradation time in vitro, from 0 to 53 weeks. Clear degradation was observed for the pure PLLA, at approximately $50{ }^{\circ} \mathrm{C}$, comparing the values of temperature peaks between 0 and 53 weeks, but this behavior is less intense for the blends PLLA/PHBV 60/40 and 40/60. Pure PHBV did not present a significant variation until 53 weeks. These results show that the thermal stability of these blends is dependent on the PLLA proportion in the blend ${ }^{11}$.

\subsection{Differential scanning calorimetry (DSC)}

DSC curves, Figs. 1 to 4, show the behavior of the blends during hydrolytic degradation. The pure polymers and the blends are characterized by a melting peak, glass transition temperature and crystallization peak, typical of semi-crystalline polymers. The crystallization peak and the glass transition temperature $\left(\mathrm{T}_{\mathrm{g}}\right)$ for PHBV are verified only on the second heating. The values can be found in Tables 2 to 5 .

After degradation the glass transition temperature $\left(\mathrm{T}_{\mathrm{g}}\right)$ became more difficult to be observed in the first heating. Data of glass transition temperatures $\left(\mathrm{T}_{\mathrm{g}}\right)$ were observed for the blends in the first or second heating. A decrease of $\mathrm{T}_{\mathrm{g}}$ values, in the second heating, for pure PLLA, in relation to the degradation time, was observed. In the case of 60/40 and 40/60 blends, there was an increase of $\mathrm{T}_{\mathrm{g}}$ of PLLA. This can be explained by the high crystallinity degree of PHBV, decreasing the mobility of the PLLA chains in these compositions. It is not possible to observe the $\mathrm{T}_{\mathrm{g}}$ for the PLLA
Table 1. Values of Initial Temperature of mass loss ( $\left.\mathrm{T}_{\text {onset }}\right)$ and Temperature of maximum mass loss ( $\mathrm{T}_{\text {peak }}$ ) for the PLLA/PHBV blends obtained by TGA, in different compositions of the blends in relation to degradation period (weeks).

\begin{tabular}{|c|c|c|c|c|}
\hline \multirow{2}{*}{$\frac{\text { weeks }}{100 / 0}$} & \multicolumn{2}{|c|}{$\mathrm{T}_{\text {onset }}\left({ }^{\circ} \mathrm{C}\right)$} & \multicolumn{2}{|c|}{$\mathrm{T}_{\text {peak }}\left({ }^{\circ} \mathrm{C}\right)$} \\
\hline & PHBV & PLLA & PHBV & PLLA \\
\hline 0 & & 330 & & 356 \\
\hline 12 & & 300 & & 337 \\
\hline 36 & & 273 & & 307 \\
\hline 53 & & 270 & & 299 \\
\hline $60 / 40$ & PHBV & PLLA & PHBV & PLLA \\
\hline 0 & 256 & 312 & 272 & 328 \\
\hline 12 & 269 & 339 & 285 & 362 \\
\hline 36 & 246 & 326 & 268 & 339 \\
\hline 53 & 231 & 307 & 253 & 325 \\
\hline $40 / 60$ & PHBV & PLLA & PHBV & PLLA \\
\hline 0 & 273 & 331 & 281 & 352 \\
\hline 12 & 258 & 316 & 267 & 336 \\
\hline 36 & 272 & 335 & 285 & 353 \\
\hline 53 & 253 & 321 & 271 & 339 \\
\hline $0 / 100$ & PHBV & PLLA & PHBV & PLLA \\
\hline 0 & 271 & & 286 & \\
\hline 12 & 270 & & 285 & \\
\hline 36 & 272 & & 287 & \\
\hline 53 & 268 & & 282 & \\
\hline
\end{tabular}

in the 60/40 and 40/60 blends in the second heating, because they are overlaid by the crystallization peak of PHBV. $\mathrm{T}_{\mathrm{g}}$ values of PHBV decrease in the blends, but the same does not occur for the pure PHBV, because the PHBV is very resistant to the hydrolytic degradation, so after degradation of PLLA the amorphous parts of PHBV acquire more mobility, decreasing $\mathrm{T}_{\mathrm{g}}$.

Up to 12 weeks of degradation, the melting temperature $\left(\mathrm{T}_{\mathrm{m}}\right)$ did not present significant variation $\left(140-160{ }^{\circ} \mathrm{C}\right.$ for PHBV and $175{ }^{\circ} \mathrm{C}$ for PLLA). Moreover, after 12 weeks the $T_{m}$ for PLLA decreased for the 100/0, 60/40 and 40/60 blends, especially for the pure PLLA, (Tables 2, 3 and 4). This occur because the degradation process of PLLA has as consequence the formation of new crystals, which can be melted with lower energy and temperature. $T_{m}$ values of PHBV showed a discreet decrease in the blends, however the same did not occur for pure PHBV, (Table 5).

A notable characteristic in the curves of DSC, obtained in this study, is the crystallization temperature of the polymers $\left(T_{c}\right)$. The $T_{c}$ of the blends showed a strong approaching tendency in relation to degradation period, (Tables 2 and 3). This can be explained by the fact that the degrada- 


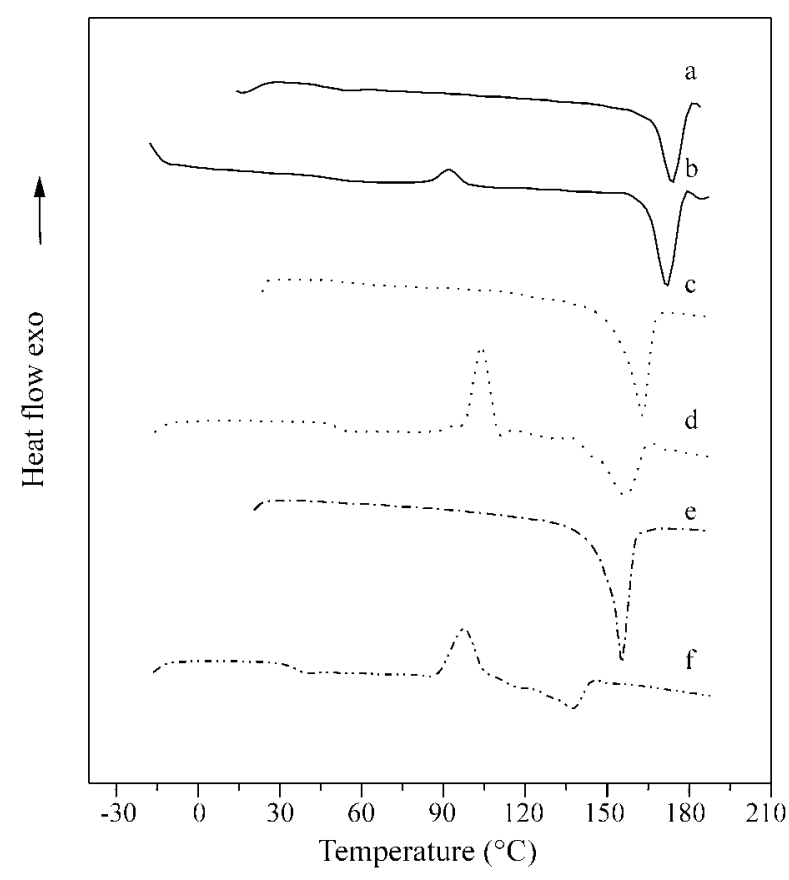

Figure 1. DSC curves for PLLA/PHBV 100/0 blends submitted to different hydrolytic degradation periods, first heating $(\mathrm{a}, \mathrm{c}, \mathrm{e})$ for 0,36 and 53 weeks, respectively and second heating $(b, d, f)$ for 0,36 and 53 weeks, respectively.

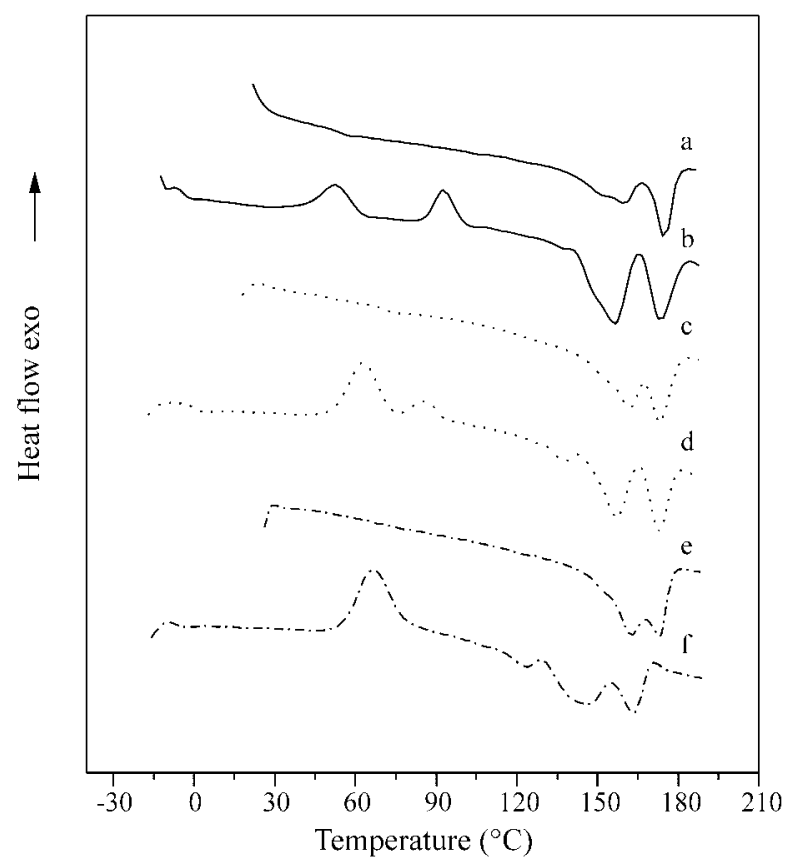

Figure 3. DSC curves for PLLA/PHBV 40/60 blends submitted to different hydrolytic degradation periods, first heating $(\mathrm{a}, \mathrm{c}, \mathrm{e})$ for 0,36 and 53 weeks, respectively and second heating $(b, d, f)$ for 0,36 and 53 weeks, respectively.

tion of amorphous part of PLLA promote mobility of the chains allowing the crystallization at the lower temperature. On the other hand the crystallization of PHBV is affected by the degradation process of PLLA.

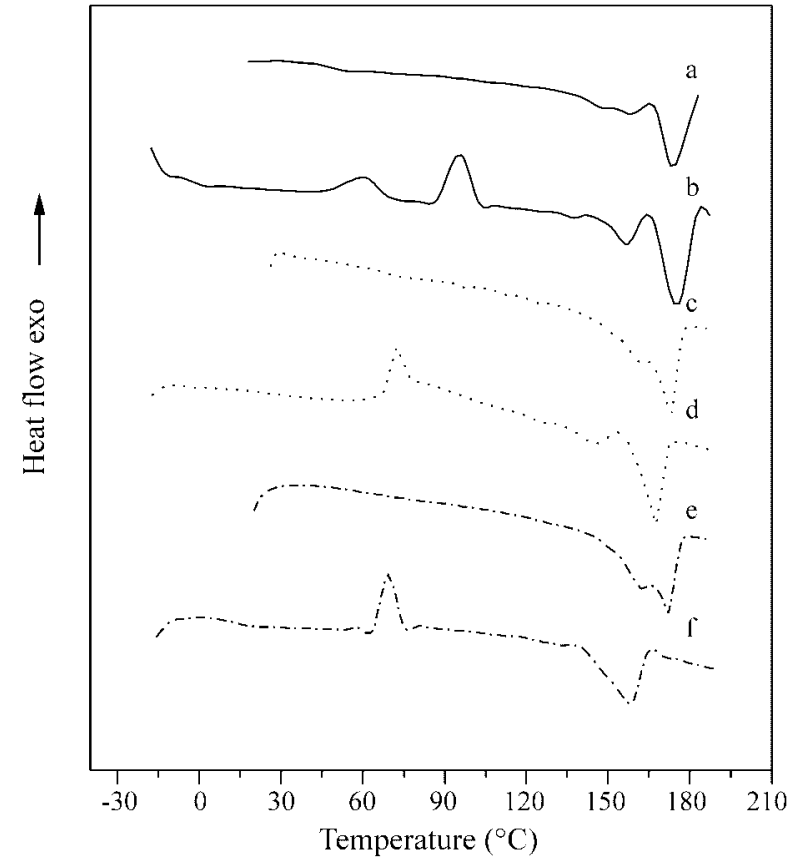

Figure 2. DSC curves for PLLA/PHBV 60/40 blends submitted to different hydrolytic degradation periods, first heating ( $(a, c, e)$ for 0,36 and 53 weeks, respectively and second heating $(b, d, f)$ for 0,36 and 53 weeks, respectively.

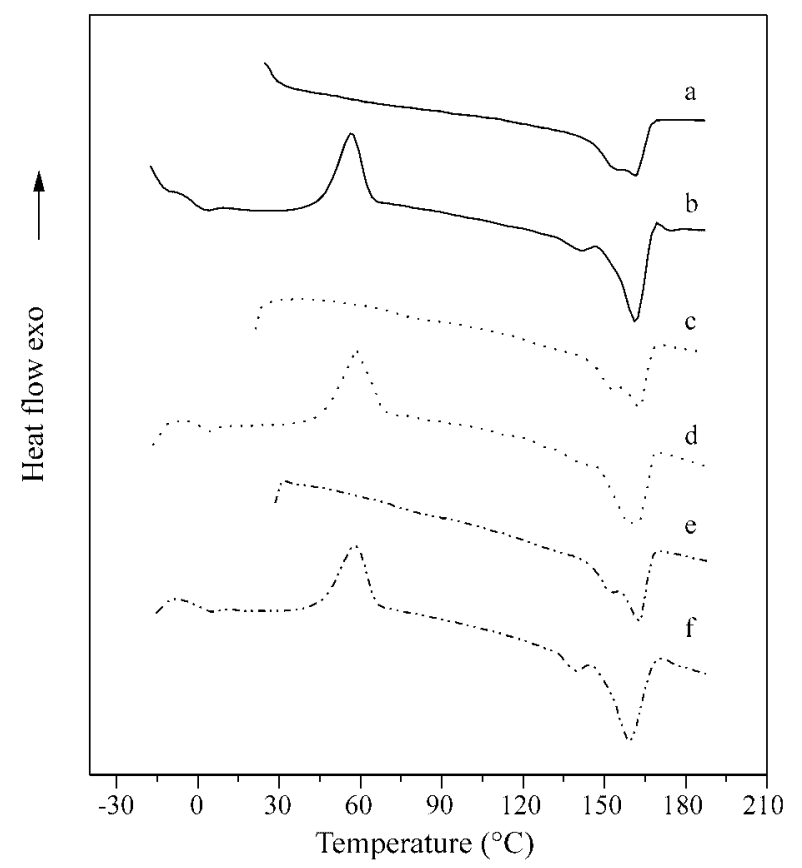

Figure 4. DSC curves for PLLA/PHBV 0/100 blends submitted to different hydrolytic degradation periods, first heating (a, c, e) for 0,36 and 53 weeks, respectively and second heating $(b, d, f)$ for 0,36 and 53 weeks, respectively.

It can also be noticed that the crystallization enthalpy $\left(\Delta \mathrm{H}_{\mathrm{c}}\right)$ of PLLA increased with the degradation of the blends, Table 2 . This increase has been greatly discussed in literature ${ }^{12}$. Many authors consider that this is due to the 
Table 2. Glass Transition ( $\left.\mathrm{T}_{\mathrm{g}}\right)$, Crystallization $\left(\mathrm{T}_{\mathrm{c}}\right)$ and Melting $\left(\mathrm{T}_{\mathrm{m}}\right)$ Temperatures; Crystallization $\left(\Delta \mathrm{H}_{\mathrm{c}}\right)$ and Melting $\left(\Delta \mathrm{H}_{\mathrm{m}}\right)$ Enthalpies; Crystallinity Degree $(\chi)$ obtained by DSC, for films of PLLA/PHBV 100/0 blends in relation to degradation period (weeks).

\begin{tabular}{|c|c|c|c|c|c|c|c|c|c|c|c|c|}
\hline \multicolumn{2}{|c|}{$100 / 0$} & \multicolumn{2}{|c|}{$\mathrm{T}_{\mathrm{g}}\left({ }^{\circ} \mathrm{C}\right)$} & \multicolumn{2}{|c|}{$\mathrm{T}_{\mathrm{c}}\left({ }^{\circ} \mathrm{C}\right)$} & \multicolumn{2}{|c|}{$\Delta \mathrm{H}_{\mathrm{c}}(\mathrm{J} / \mathrm{g})$} & \multicolumn{2}{|c|}{$\mathrm{T}_{\mathrm{m}}\left({ }^{\circ} \mathrm{C}\right)$} & \multicolumn{2}{|c|}{$\Delta \mathrm{H}_{\mathrm{m}}(\mathrm{J} / \mathrm{g})$} & \multirow{2}{*}{$\begin{array}{l}\chi(\%) \\
\text { PLLA }\end{array}$} \\
\hline Weeks & Heating & PHBV & PLLA & PHBV & PLLA & PHBV & PLLA & PHBV & PLLA & PHBV & PLLA & \\
\hline \multirow[t]{2}{*}{0} & $1^{\circ}$ & & 47 & & & & & & 175 & & 39 & 42 \\
\hline & $2^{\circ}$ & & 49 & & 93 & & 8 & & 173 & & 42 & \\
\hline \multirow[t]{2}{*}{12} & 1 & & 54 & & & & & & 170 & & 52 & 55 \\
\hline & $2^{\circ}$ & & 52 & & 92 & & 5 & & 167 & & 44 & \\
\hline \multirow[t]{2}{*}{36} & $1^{\circ}$ & & & & & & & & 163 & & 56 & 60 \\
\hline & $2^{\circ}$ & & 51 & & 105 & & 31 & & 157 & & 36 & \\
\hline \multirow[t]{2}{*}{53} & 1 & & & & & & & & 156 & & 70 & 75 \\
\hline & $2^{\circ}$ & & 35 & & 97 & & 28 & & 137 & & 24 & \\
\hline
\end{tabular}

Table 3. Glass Transition $\left(\mathrm{T}_{\mathrm{g}}\right)$, Crystallization $\left(\mathrm{T}_{\mathrm{c}}\right)$ and Melting $\left(\mathrm{T}_{\mathrm{m}}\right)$ Temperatures; Crystallization $\left(\Delta \mathrm{H}_{\mathrm{c}}\right)$ and Melting $\left(\Delta \mathrm{H}_{\mathrm{m}}\right)$ Enthalpies; Crystallinity Degree $(\chi)$ obtained by DSC, for films of PLLA/PHBV 60/40 blends in relation to degradation period (weeks).

\begin{tabular}{|c|c|c|c|c|c|c|c|c|c|c|c|c|}
\hline \multicolumn{2}{|c|}{$60 / 40$} & \multicolumn{2}{|c|}{$\mathrm{T}_{\mathrm{g}}\left({ }^{\circ} \mathrm{C}\right)$} & \multicolumn{2}{|c|}{$\mathrm{T}_{\mathrm{c}}\left({ }^{\circ} \mathrm{C}\right)$} & \multicolumn{2}{|c|}{$\Delta \mathrm{H}_{\mathrm{c}}(\mathrm{J} / \mathrm{g})$} & \multicolumn{2}{|c|}{$\mathrm{T}_{\mathrm{m}}\left({ }^{\circ} \mathrm{C}\right)$} & \multicolumn{2}{|c|}{$\Delta \mathrm{H}_{\mathrm{m}}(\mathrm{J} / \mathrm{g})$} & \multirow{2}{*}{$\begin{array}{l}\chi(\%) \\
\text { PLLA }\end{array}$} \\
\hline Weeks & Heating & PHBV & PLLA & PHBV & PLLA & PHBV & PLLA & PHBV & PLLA & PHBV & PLLA & \\
\hline \multirow[t]{2}{*}{0} & $1^{\circ}$ & & 48 & & & & & 158 & 175 & 6 & 19 & 34 \\
\hline & $2^{\circ}$ & -1 & & 60 & 95 & 9 & 15 & $138-158$ & 175 & 13 & 27 & \\
\hline \multirow[t]{2}{*}{12} & 1 & & 67 & & & & & 163 & 176 & 5 & 19 & 34 \\
\hline & $2^{\circ}$ & 1 & & 67 & 90 & 7 & 10 & $140-158$ & 176 & 14 & 27 & \\
\hline \multirow[t]{2}{*}{36} & $1^{\circ}$ & & 69 & & & & & 162 & 173 & 2 & 12 & 21 \\
\hline & $2^{\circ}$ & -6 & & 73 & & 27 & & 147 & 168 & 10 & 24 & \\
\hline \multirow[t]{2}{*}{53} & 1 & & & & & & & 163 & 172 & 3 & 7 & 12 \\
\hline & $2^{\circ}$ & & & 70 & & 10 & & 158 & & 21 & & \\
\hline
\end{tabular}

Table 4. Glass Transition ( $\left.\mathrm{T}_{\mathrm{g}}\right)$, Crystallization $\left(\mathrm{T}_{\mathrm{c}}\right)$ and Melting $\left(\mathrm{T}_{\mathrm{m}}\right)$ Temperatures; Crystallization $\left(\Delta \mathrm{H}_{\mathrm{c}}\right)$ and Melting $\left(\Delta \mathrm{H}_{\mathrm{m}}\right)$ Enthalpies; Crystallinity Degree $(\chi)$ obtained by DSC, for films of PLLA/PHBV 40/60 blends in relation to degradation period (weeks).

\begin{tabular}{|c|c|c|c|c|c|c|c|c|c|c|c|c|}
\hline \multicolumn{2}{|l|}{$40 / 60$} & \multicolumn{2}{|c|}{$\mathrm{T}_{\mathrm{g}}\left({ }^{\circ} \mathrm{C}\right)$} & \multicolumn{2}{|c|}{$\mathrm{T}_{\mathrm{c}}\left({ }^{\circ} \mathrm{C}\right)$} & \multicolumn{2}{|c|}{$\Delta \mathrm{H}_{\mathrm{c}}(\mathrm{J} / \mathrm{g})$} & \multicolumn{2}{|c|}{$\mathrm{T}_{\mathrm{m}}\left({ }^{\circ} \mathrm{C}\right)$} & \multicolumn{2}{|c|}{$\Delta \mathrm{H}_{\mathrm{m}}(\mathrm{J} / \mathrm{g})$} & \multirow{2}{*}{$\frac{\chi(\%)}{\text { PLLA }}$} \\
\hline Weeks & Heating & PHBV & PLLA & PHBV & PLLA & PHBV & PLLA & PHBV & PLLA & PHBV & PLLA & \\
\hline \multirow[t]{2}{*}{0} & $1^{\circ}$ & & 52 & & & & & 160 & 175 & 11 & 10 & 27 \\
\hline & $2^{\circ}$ & & & 53 & 93 & 9 & 8 & 157 & 175 & 25 & 14 & \\
\hline \multirow[t]{2}{*}{12} & 1 & & 66 & & & & & 163 & 176 & 11 & 10 & 27 \\
\hline & $2^{\circ}$ & 2 & & 66 & 97 & 15 & 7 & $142-161$ & 177 & 18 & 14 & \\
\hline \multirow[t]{2}{*}{36} & $1^{\circ}$ & & 71 & & & & & 162 & 174 & 9 & 10 & 27 \\
\hline & $2^{\circ}$ & 1 & & 63 & 85 & 17 & 4 & $138-158$ & 174 & 20 & 13 & \\
\hline \multirow[t]{2}{*}{53} & 1 & & & & & & & 163 & 173 & 6 & 5 & 13 \\
\hline & $2^{\circ}$ & -6 & & 67 & & 27 & & $123-147$ & 164 & 16 & 8 & \\
\hline
\end{tabular}

rearrangement of small chains generated by the degradation process itself, forming new crystals; others consider that the degradation of the amorphous regions of the polymers just results in an increase of the remaining crystalline regions ${ }^{12}$. The authors believe that a rearrangement of the crystals is occurring, because the degradation of PLLA results an increase of crystallization temperature of PHBV, approaching the crystallization peaks of the polymers. This 
Table 5. Glass Transition $\left(\mathrm{T}_{\mathrm{g}}\right)$, Crystallization $\left(\mathrm{T}_{\mathrm{c}}\right)$ and Melting $\left(\mathrm{T}_{\mathrm{m}}\right)$ Temperatures; Crystallization $\left(\Delta \mathrm{H}_{\mathrm{c}}\right)$ and Melting $\left(\Delta \mathrm{H}_{\mathrm{m}}\right)$ Enthalpies; obtained by DSC, for films of PLLA/PHBV 0/100 blends in relation to degradation period (weeks).

\begin{tabular}{|c|c|c|c|c|c|c|c|c|c|c|c|}
\hline \multicolumn{2}{|c|}{$0 / 100$} & \multicolumn{2}{|c|}{$\mathrm{T}_{\mathrm{g}}\left({ }^{\circ} \mathrm{C}\right)$} & \multicolumn{2}{|c|}{$\mathrm{T}_{\mathrm{c}}\left({ }^{\circ} \mathrm{C}\right)$} & \multicolumn{2}{|c|}{$\Delta \mathrm{H}_{\mathrm{c}}(\mathrm{J} / \mathrm{g})$} & \multicolumn{2}{|c|}{$\mathrm{T}_{\mathrm{m}}\left({ }^{\circ} \mathrm{C}\right)$} & \multicolumn{2}{|c|}{$\Delta \mathrm{H}_{\mathrm{m}}(\mathrm{J} / \mathrm{g})$} \\
\hline Weeks & Heating & PHBV & PLLA & PHBV & PLLA & PHBV & PLLA & PHBV & PLLA & PHBV & PLLA \\
\hline 0 & $1^{\circ}$ & & & & & & & $156-161$ & & 30 & \\
\hline & $2^{\circ}$ & -2 & & 57 & & 25 & & $141-161$ & & 38 & \\
\hline 12 & 1 & & & & & & & $153-162$ & & 28 & \\
\hline & $2^{\circ}$ & 0 & & 59 & & 28 & & $141-161$ & & 43 & \\
\hline 36 & $1^{\circ}$ & & & & & & & $153-163$ & & 28 & \\
\hline & $2^{\circ}$ & -1 & & 59 & & 28 & & $142-161$ & & 35 & \\
\hline 53 & 1 & & & & & & & $153-162$ & & 30 & \\
\hline & $2^{\circ}$ & 0 & & 58 & & 27 & & $140-161$ & & 41 & \\
\hline
\end{tabular}

fact is discussed by Penning and collaborators ${ }^{9}$. The authors suggest the occurrence of co-crystallization of the system.

A priori, the method used to obtain the films allowed a complete crystallization, so the thermograms do not present $\mathrm{T}_{\mathrm{c}}$ in the first heating. However, in the second heating the crystallization enthalpy $(\Delta \mathrm{Hc})$ occurred, due to the fact that the cooling rate was fast enough hindering the complete crystallization $^{12}$.

Another point to be observed is that the PLLA suffers more intense hydrolytic degradation, because it was the polymer that demonstrated larger alteration in its thermal properties. Holland and collaborators show that PHBV (with $12 \%$ of $\mathrm{HV}$ ) begins its mass loss, at $\mathrm{pH} 7.4$, around 25 days, but at $70{ }^{\circ} \mathrm{C}$. The same occurs at $37^{\circ} \mathrm{C}$, but with $\mathrm{pH}$ 10.6. It also showed that PHBV did not suffer mass loss until 120 days $\left(\mathrm{pH} 7.4 \text { at } 37^{\circ} \mathrm{C}\right)^{13}$. In this study, changes in the thermal properties of pure PHBV were observed only after being submitted to a degradation process for 53 weeks.

Using the melting enthalpy, and calculated melting enthalpy of PLLA, considering the polymer $100 \%$ crystalline $(93.7 \mathrm{~J} / \mathrm{g})^{14}$, it was possible to obtain the crystallinity degree $(\chi \%)$ of PLLA in the blend

$$
\chi=\frac{\Delta \mathrm{H}_{\mathrm{m}}}{\Delta \mathrm{H}_{\mathrm{m}}^{0}} \times 100
$$

where: $\Delta \mathrm{H}_{\mathrm{m}}=$ experimental melting enthalpy $[\mathrm{J} / \mathrm{g}]$ and $\Delta \mathrm{H}_{\mathrm{m}}$ ${ }^{\circ}=93.7 \mathrm{~J} / \mathrm{g}^{14}$.

The values of $\Delta \mathrm{H}_{\mathrm{m}}$ obtained from the analysis of DSC were recalculated considering the composition of the polymer in the blend. Values obtained for the crystallinity degree are in Tables 2 to 4 . An increase of the crystallinity degree for pure PLLA in relation to the degradation time can be observed. This increase became the samples more brittle, decreasing their mechanical properties. On the other hand, the crystallinity degree of PLLA decreased in
PLLA/PHBV 60/40 and 40/60 blends. This can suggest that the presence of PHBV in the blend hinders the crystallization of PLLA.

\subsection{Dynamic mechanical analysis (DMA)}

Table 6 shows the values obtained for the PLLA/PHBV blends in different compositions and submitted to different degradation periods. Pure PLLA presented a fast loss of mechanical properties due to the degradation process. After one week in a phosphate buffer solution, it was not possible to analyze the samples by DMA, however the increase of PHBV in the blend improved the mechanical properties. For pure PHBV it was possible to carry out all the analysis up to 36 weeks under degradation conditions.

Table 6 shows two glass transition temperature values for the blends from Loss Modulus (E') and damping ( $\tan \delta$ ). Comparing $\mathrm{Tg}$ values obtained before degradation for pure polymers and blends, it is possible verify a minimal variation among these values. As verified in DSC data, this suggests the immiscibility of blends components.

The Tg values for the 60/40 and 40/60 blends increased in relation to degradation. This increase was more intense for a higher level of PHBV in the blend. As already discussed before, this increase can be due to the fact that the presence of PHBV decreases mobility of the PLLA chains.

It is possible to observe, by DMA analysis (Figs. 5, 6 and 7), a variation in the crystallization of the samples by storage modulus curves (E'). According to literature ${ }^{15}$, when the sample becomes more crystalline, the absolute value of the storage modulus (E') increases and the peak of the $\tan \delta$ decreases. This behavior was observed for the blends in this study.

\subsection{Analysis of scanning electron microscopy (SEM)}

In spite of the great loss of mechanical properties of the blends, which making the samples into very small fragile fragments in a short time (12 weeks) of immersion in 
Table 6. Glass Transition Temperatures ( $\mathrm{T}_{\mathrm{g}}$ ) obtained by DMA, on the curves of Loss Modulus (E") and damping ( $\tan \delta$ ), for the blends in different compositions and degradation period (weeks).

\begin{tabular}{lcllll}
\hline PLLA/PHBV & \multicolumn{2}{c}{$\mathrm{T}_{\mathrm{g}}\left({ }^{\circ} \mathrm{C}\right)-\mathrm{E}{ }^{\prime}}$, & & \multicolumn{2}{c}{$\mathrm{T}_{\mathrm{g}}\left({ }^{\circ} \mathrm{C}\right)-\tan \delta$} \\
\cline { 2 - 3 } \cline { 5 - 6 } Weeks & PHBV & PLLA & & PHBV & PLLA \\
\hline
\end{tabular}

$100 / 0$

0

1

$60 / 40$

\begin{tabular}{lcccc}
0 & 18 & 66 & 26 & 81 \\
1 & 13 & 72 & 17 & 85 \\
2 & 14 & 76 & 18 & 87 \\
4 & 16 & 79 & 19 & 90 \\
$40 / 60$ & & & & \\
0 & 9 & 67 & 16 & - \\
2 & 13 & 77 & 20 & - \\
4 & 13 & 80 & 19 & - \\
12 & 16 & 78 & 21 & - \\
16 & 19 & 84 & 24 & - \\
$0 / 100$ & & & & \\
0 & 10 & & 17 & \\
2 & 12 & & 18 & \\
4 & 11 & & 18 & \\
12 & 8 & & 15 & \\
16 & 16 & & 22 & \\
24 & 17 & & 23 & \\
36 & 16 & & 23 & \\
\hline
\end{tabular}

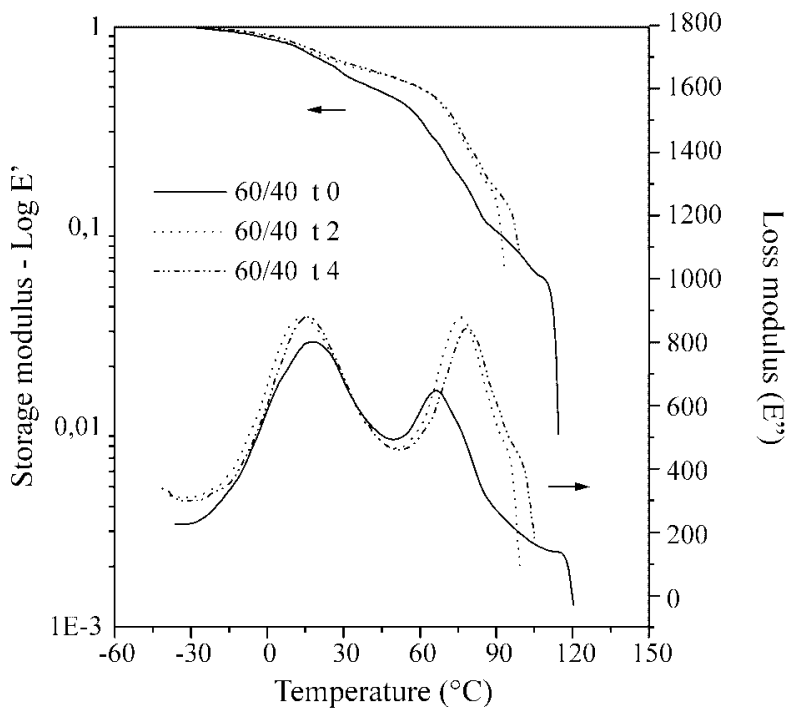

Figure 5. DMA curves for PLLA/PHBV $60 / 40$ blends in relation to degradation periods $0,2,4$ weeks. phosphate buffer solution, it was not possible to observe, by microscopy, evident degradation during this period.

Figure 8 shows micrographs of blends in different compositions for degraded and non-degraded blends. It can be observed that the blends showed a porous morphology on the upper surface, except for pure PHBV, and the distribution of the porous increased with the increase of the PLLA concentration.

Observing non-degraded 60/40 and 40/60 blends, (Figs. $8 \mathrm{c}$ and $8 \mathrm{e}$ ), it is possible to verify a discrete phase separation, as verified by Iannace and colaborators ${ }^{8}$.

PLLA/PHBV 100/0 blends began to present some signals of degradation after 8 weeks and this was more intense after 16 weeks, (Fig. 8b). At larger periods of time it was

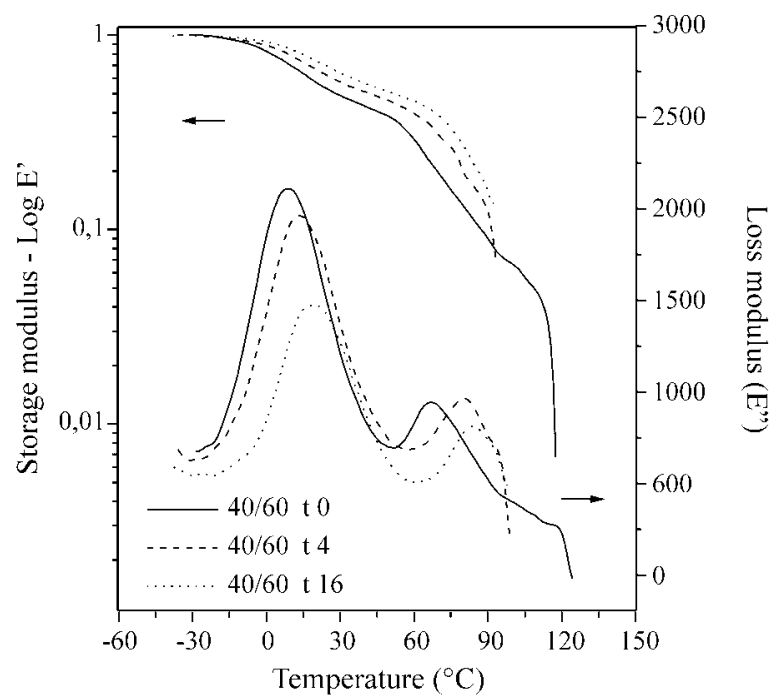

Figure 6. DMA curves for PLLA/PHBV $40 / 60$ blends in relation to degradation periods $0,4,16$ weeks.

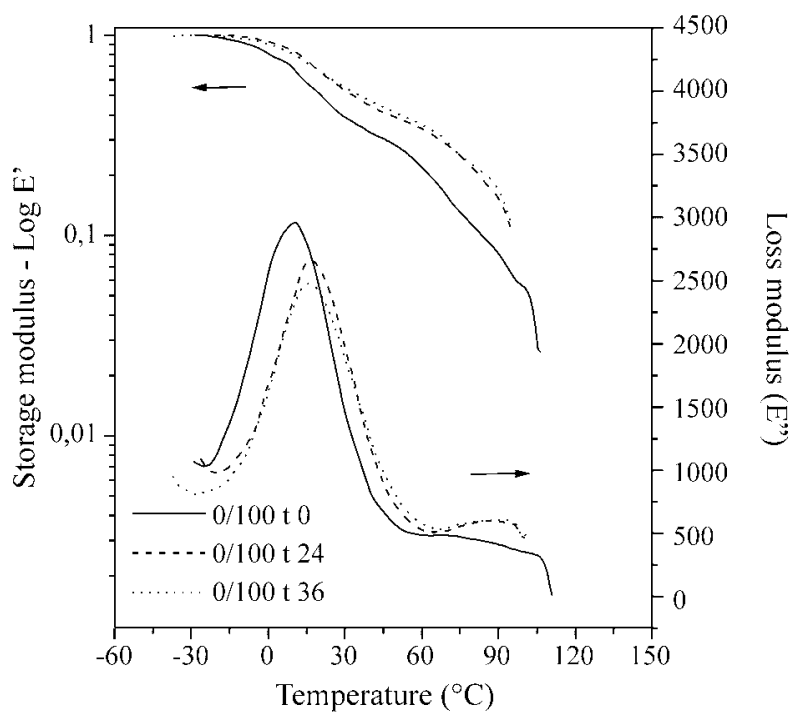

Figure 7. DMA curves for PLLA/PHBV 0/100 blends in relation to degradation periods $0,24,36$ weeks. 


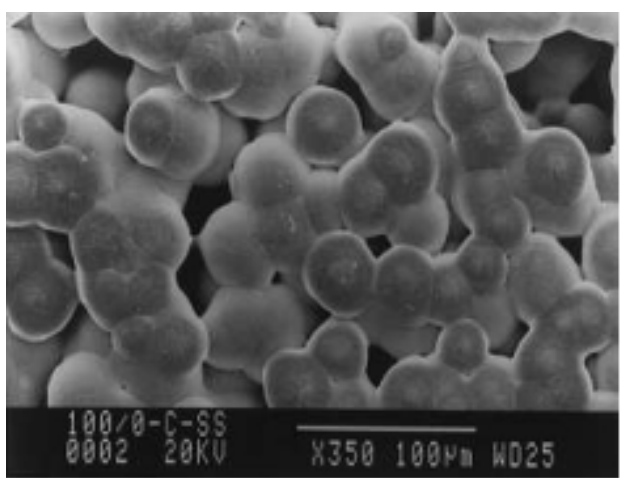

(a)

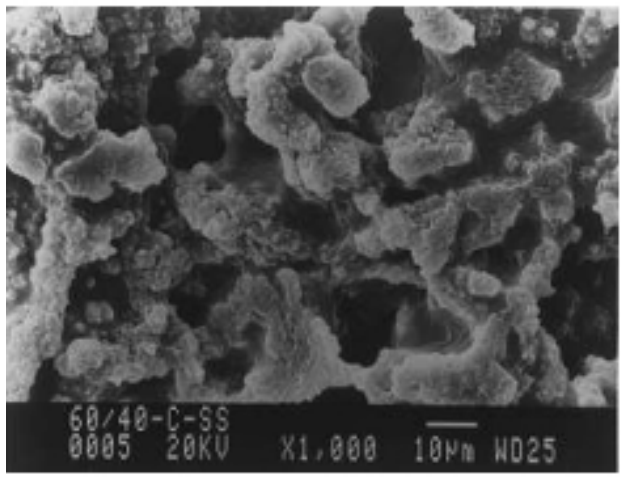

(c)

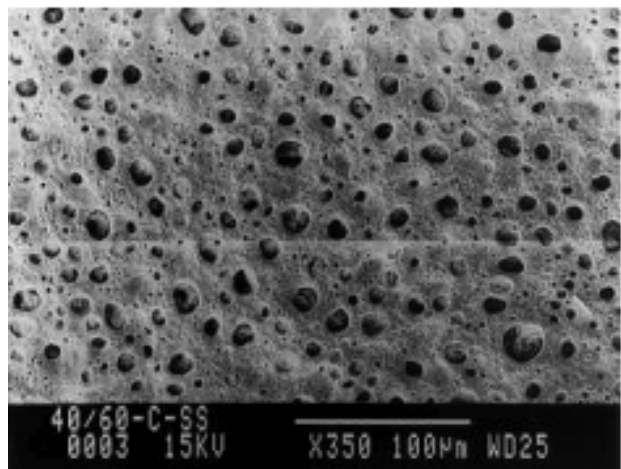

(e)

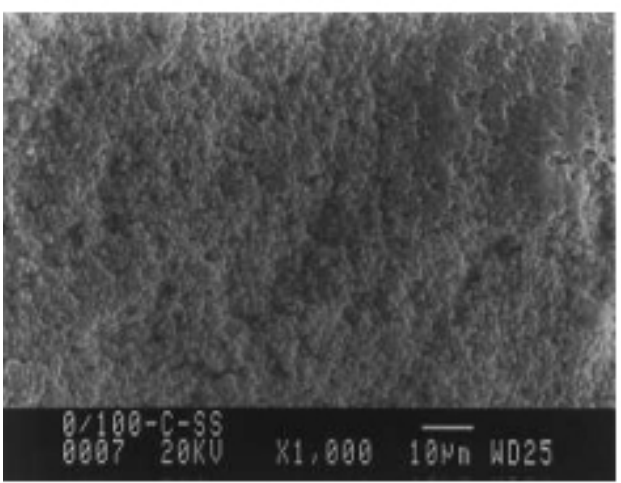

(g)

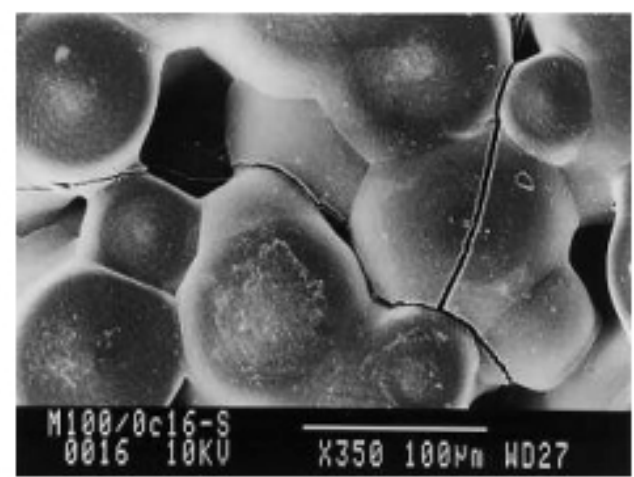

(b)

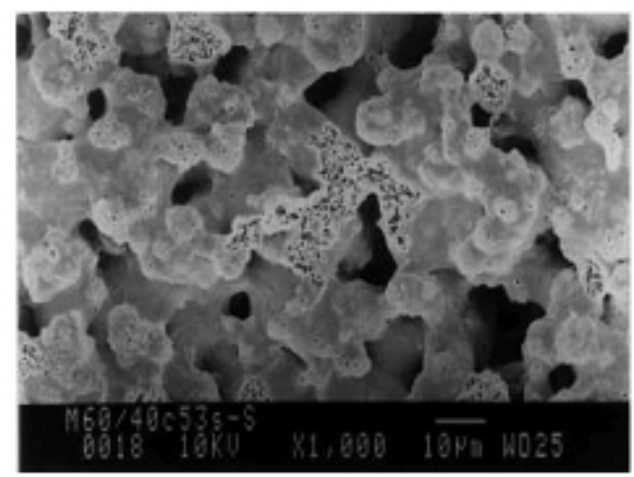

(d)

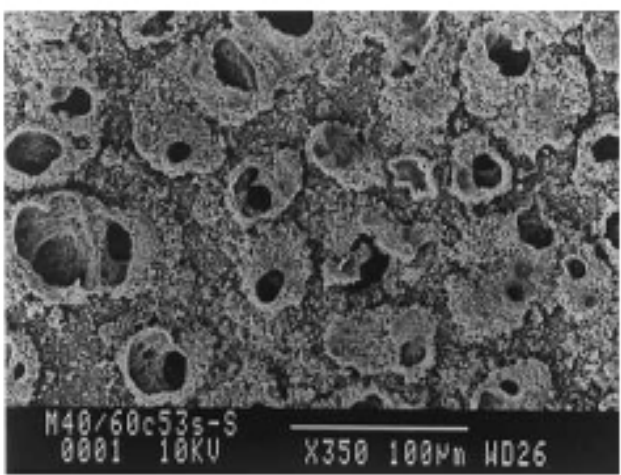

(f)

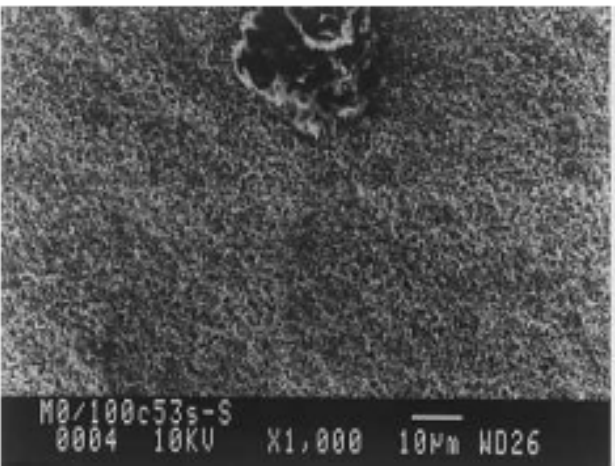

(h)

Figure 8. Electron micrographs of upper surfaces of PLLA/PHBV blends of different compositions and submitted to different degradation periods: 100/0 (a), 60/40 (c), 40/60 (e) and 0/100 (g), t = 0 weeks; 100/0 (b), $\mathrm{t}=16$ weeks; 60/40 (d), 40/60 (f) and 0/100 (h), t = 53 weeks. 
not possible to prepare the samples for microscopy analysis, due to their fragility.

Figures $8 \mathrm{~d}$ and $8 \mathrm{f}$ show the upper surfaces of blends $60 / 40$ and 40/60, respectively. A clear degradation process, after 53 weeks compared to samples without degradation, can be observed, (Figs. 8c and 8e). For PHBV, Fig. 8h, discrete signals of degradation up to 53 weeks were noticed.

\section{Conclusion}

Thermogravimetric analysis (TGA) data showed that the initial temperature of loss mass $\left(\mathrm{T}_{\text {onset }}\right)$ for pure PLLA decreased with degradation time. The same occurred for PLLA/PHBV 60/40 and 40/60 blends, but with lower intensity. For pure PHBV the $\mathrm{T}_{\text {onset }}$ did not vary.

Differential scanning calorimetry (DSC) data showed the presence of two glass transition temperatures for the PLLA/PHBV 60/40 and 40/60 blends, and crystallization at different temperatures. Moreover, crystallization temperature values showed a strong approaching tendency in relation to degradation time. The crystallinity degree for pure PLLA increased, but for the PLLA/PHBV 60/40 and $40 / 60$ blends, it decreased in relation to degradation time. It can be attribute to the presence of PHBV in the blend hindered the crystallization of PLLA. The increase in the crystallinity degree of pure PLLA became the films brittle.

In the dynamic mechanical analysis (DMA) the immiscibility of the blends, can be observed, confirming DSC data.

Using scanning electron microscopy it can be observed a porous morphology for upper surface of the blends, except for pure PHBV. The blends showed a discrete phase separation. All the blends showed signals of degradation after immersion in a phosphate buffer solution, and this intensity increased with the increase of PLLA in the blends.

\section{Acknowledgments}

The authors are grateful to FAPESP (proc. 97/14275-7 and 97/06268-0) and FINEP/Pronex for financial support of this work.

\section{References}

1. Wake, M.C. et al. Effects of biodegradable polymer particles on rat marrow-derived stromal osteoblasts in vitro. Biomaterials, v. 19, p. 1255-1268, 1998.

2. Grimaldi, M. et al. Reactive processing-property relationships in biodegradable blends useful goes prosthesis application. Journal of Materials Science, v. 31, p.6155-6162, 1996.
3. Rehman, I.; Andrews, E.H.; Smith, R. In vitro degradation of poly(esther-urethanes) it goes biomedical applications. Journal of Materials Science: Material in Medicine, v. 7, p. 17-20, 1996.

4. Knowles, J.C.; Hastings, G.W. In vitro degradation of $\mathrm{PHB} / \mathrm{PHV}$ copolymer and the new technique goes monitoring early surface changes. Biomaterials, v. 12, p. 210-214, 1991.

5. Blümm, E.; Owen, A.J. Miscibility, crystallization and melting of poly(3-hydroxybutyrate)/poly(L-lactide) blends. Polymer, v. 36, n. 21, p. 4077-4081, 1995.

6.Zhang, L.; Xiong, C.; Deng, X. Biodegradable polyesters blends goes biomedical apllication. Journal of Applied Polymer Science, v. 56, p. 103-112, 1995.

7.Park, T.G.; Cohen, S. Langer, R. Poly(L-lactic acid)/Pluronic blends: characterization of phase separation behavior, degradation, and morphology and uses the protein-releasing matrices. Macromolecules, v. 25, p. 116-122, 1992.

8. Iannace, S.; Ambrosio, L.; Huang, S.J.; Nicolais, L. Poly(3-hydroxybutyrate)-co-(3-hydroxyvalerate)/Po ly-L-lactide blends: thermal and mechanical properties, Journal of Applied Polymer Science, v. 54, p. 1525-1536, 1994.

9. Penning, J.P.; Manley, R.St.J. Miscible blends of two crystalline polymers. 2. Crystallization kinetics and morphology in blends of poly(vinylidene fluoride) and poly(1,4-butylene adipate). Macromolecules, v. 29, p. 84-90, 1996.

10. Ultracki, L.A. Polymer, Alloys and Blends. Thermodynamics and Rheology. Ed. Hanser, New York, 1989.

11. Turi, E.A. Thermal characterization of polymeric materials. Ed. Academic Press, Inc., London, 1981.

12. Duek, E.A.R.; Zavaglia, C.A.C.; Belangero, W.D. In vitro study of poly(lactic acid) pin degradation. Polymer, v. 40, p. 6465-6473, 1999.

13. Holland, S.J.; Yasin, M.; Tighe, B.J. Polymers goes biodegradable medical devices. VII. Hydroxybutyrate-hydroxyvalerate copolymers: degradation of copolymers and their blends with polysaccharides under in vitro physiological conditions. Biomaterials, v. 11, p. 208-215, 1990.

14. Fisher, E.W.; Sterzel, H.J.; Wegner, G. Investigation of the structure of solution grown crystals of lactide copolymers by means of chemical reactions. KolloidZ Z Polymere. v. 251, p. 980-990, 1973.

15. Nielsen, L.E. Mechanical Properties of Polymers and Composites, Marcel Dekker, N.Y., v. 1, 1974. 